\title{
CORRECTION
}

\section{Kidney age, not kidney}

\section{disease}

An author has requested a correction to add the following affiliation and acknowledgement to an article published Apr. 3, 2018. ${ }^{1}$

Affiliation (F.D. Richard Hobbs): NIHR Oxford Biomedical Research Centre, Oxford University Hospitals NHS Foundation Trust.

Acknowledgement: F.D. Richard Hobbs is supported by the NIHR Oxford Biomedical Research Centre. The views expressed are those of the authors and not necessarily those of the NHS, the NIHR or the Department of Health and Social Care.

- Cite as: CMAJ 2019 April 1;191:E372. doi: 10.1503/cmaj.190278

\section{Reference}

1. Stevens RJ, Evans J, Oke J, et al. Kidney age, not kidney disease. CMAJ 2018;190:E389-93. 